\title{
Agricultural Recycling of BFT Inland Aquaculture Effluent for Blueberry 'Duke' Cultivation
}

\author{
Yong Hyun Kim ${ }^{1,2}$, Moo Ryong Huh ${ }^{1,2} *$, Jeong Ho Lee ${ }^{3}$, Young Sik Lee ${ }^{3}$, and Hye Sung Choi ${ }^{4}$ \\ ${ }^{1}$ Department of Horticulture, Gyeongsang National Univ., Jinju 52828, South Korea \\ ${ }^{2}$ Institute of Agriculture \& Life Science, Gyeongsang National Univ., Jinju 52828, South Korea \\ ${ }^{3}$ Inland Aquaculture Research Center, National Institue of Fisheries Science, Jinhae 51691, South Korea \\ ${ }^{4}$ Southwest Sea Fisheries Research Institute, National Institute of Fisheries Science, Yeosu 59780, South Korea
}

\begin{abstract}
As an aquaculture effluent is recognized as a source of water pollution, many methods are being researched to solve this problem. It has been reported that the aquaculture effluent contains many organic compounds containing nitrogen, phosphorus, potassium, and calcium. The purpose of this study was to investigate the possibility of using the effluent from bio-floc technology (BFT) inland aquaculture for fertilizing blueberry 'Duke' to promote the growth. The experiment was conducted in a commercial blueberry farm in Jinju, Gyeongsangnam-do, where blueberries are actually cultivated in order to find out the effects of fertilizers in situ. The experiment was carried out with five treatments: control with only irrigation, conventional nutrient solution fertigation, and the fertigation with three concentrations $(\times 1, \times 0.5$, or $\times 0.25)$ of effluent from BFT (Bio-Floc Technology) inland aquaculture. The treatment period was from the beginning of April, when a new leaf of blueberry began to develop, to the middle of June, when the blueberry was harvested, for a total of 10 weeks. As a result of the experiment, the treatments with effluent from BFT inland aquaculture showed better growth qualities than those of control and conventional cultivation. However, there was no statistically significant difference among all treatments regarding the total fruit production. Based on these results, it was concluded that the effluent from BFT inland aquaculture can be used for the cultivation of blueberry because it is equivalent to conventional cultivation method. This study provided a new viewpoint of recycling the effluent from BFT for agricultural purpose to reduce water pollution problems due to aquaculture wastewater.
\end{abstract}

Keywords: alternative fertilizer, recycling effluent water, resource virtuous cycle, solution to water pollution

\section{Introduction}

Consumers' interest in health as well as health-oriented color foods has been growing in modern society, and, in particular, black foods that have been known to be effective to loose weight and prevent aging are gaining more attention recently (Oh, 2007). As people's interest in black foods is growing and blueberry was selected among the top 10 healthy foods by New York Times, it has been introduced as a healthy food on TV shows and in the media and blueberry consumption has rapidly increased (Cho, 2010). As the consumption of blueberry increases, the size of production areas in

This study was supported by a grant of the National Institute of Fisheries Science titled the "Development of Fish Bio-floc Farming Technology (BFT) (R2016019).”

Received: November 17, 2017, Revised: December 8, 2017, Accepted: December 21, 2017

*Comesponding author: yonghyun@gnu.ac.kr

(C) 2017 by the Society for People, Plants, and Environment. This is an Open Access article distributed under the terms of the Creative Commons Attribution Non-Commercial License (http://creativecommons.org/licenses/by-nc/4.0/) which permits unrestricted non-commercial use, distribution, and reproduction in any medium, provided the original work is properly cited. 
Korea has rapidly expanded from 112 ha in 2007 to 1,082 ha in 2011 to 1,516 ha in 2013 (RDA, 2011; Kim et al., 2013).

BFT aquaculture farms are using bio-floc technology (BFT), an eco-friendly farming method that treats the organic nitrogen of the excreta of fish and feed residues using microorganisms to reduce pollution sources (Cho et al., 2015). In addition, effluent from aquaculture farms has been recognized as a source of pollution and treating effluent has been raised as an issue (Lee, 2001). Kim et al. (2016a) pointed out that effluent from BFT aquaculture farms contains a variety of components that are useful for the growth of plants, such as organic nitrogen, phosphorus and potassium, and thus can be used to cultivate plants. In order to re-use effluent from BFT aquaculture farms in agricultural businesses, it was compared with chemical fertilizers that have been widely used to cultivate various vegetables such as lettuce, eggplant, pepper and tomato, and there was no significant difference between the effluent and chemical fertilizers, which proves its usability in agricultural businesses (Kim et al., 2016a; 2016b; 2017). These studies, however, designed experiments in actual farms to prove the effectiveness of fertilizers and mentioned the effectiveness of effluent from BFT aquaculture farms.

In this regard, this study aimed to examine the effects of effluent from BFT aquaculture farms on the cultivation of blueberry that has gained attention recently and grown in larger areas, to compare it with cultivation methods used in actual blueberry farms, and thus to examine the possibility of using effluent from BFT aquaculture farms as a fertilizer in actual agricultural farms.

\section{Methods}

\section{Materials and Methods}

The cultivation experiment was conducted in G blueberry farm located in Jiphyeon-myeon Jinju, Gyeongsangnam-do for a total of 10 weeks from April 8 to June 17, 2016. In this study, 3-year old Vaccinium spp. 'Duke,' a variety of blueberry grown in an open field was used, and treated as shown in the following table. For each treatment, 3 plants were selected using completely randomized design (CRD).

Plants were divided into 5 groups: the control group, the conventional group (not treated with effluent, but using a conventional nutrient solution), the OEW (original effluent water) group, the HEW (half strength effluent water) group, and the QEW (quarter strength of effluent water) group (Table 1). The control group was watered with 3L of water one time per week and the conventional group was fertigated with $3 \mathrm{~L}$ of the nutrient solution that is conventionally used in farms one time per week. The OEW group was fertigated with $3 \mathrm{~L}$ of the original effluent water emitted from a BFT aquaculture farm one time per week, and the HEW group was fertigated with the half strength effluent water diluted with water emitted from a BFT aquaculture farm one time per week. The QEW group was fertigated with $3 \mathrm{~L}$ of the quarter strength effluent water diluted with water emitted from a BFT aquaculture farm one time per week. The pH level of the effluent used in this study was 5.5, and its Electrical Conductivity (EC) was $0.74 \mathrm{dS} \cdot \mathrm{m}^{-1}$. It contained $\mathrm{NH}_{4}-\mathrm{N}_{10.58} \mathrm{mg} \cdot \mathrm{L}^{-1}$,

Table 1. Experimental treatment methods of effluent fertilizer for blueberry cultivation.

\begin{tabular}{lc}
\hline Treatment & Method \\
\hline Control & Water 3 L one time per week \\
Conventional & Conventional nutrient solution 3 L per week \\
OEW & Original effluent water 3 L per week \\
HEW & Half strength effluent water 3 L per week \\
QEW & Quarter strength effluent water 3 L per week \\
\hline
\end{tabular}


Table 2. Components of original effluent water from BFT inland aquaculture.

\begin{tabular}{|c|c|c|c|c|c|c|c|c|c|c|}
\hline \multirow{2}{*}{$\mathrm{pH}$} & $\mathrm{EC}$ & $\mathrm{NH}_{4}-\mathrm{N}$ & $\mathrm{NO}_{3}-\mathrm{N}$ & $\mathrm{K}$ & $\mathrm{Ca}$ & $\mathrm{Mg}$ & $\mathrm{Na}$ & $\mathrm{Cl}$ & $\mathrm{PO}_{4}-\mathrm{P}$ & $\mathrm{Fe}$ \\
\hline & $\mathrm{dS} \cdot \mathrm{m}^{-1}$ & & & & & $\mathrm{mg} \cdot \mathrm{L}^{-1}$ & & & & \\
\hline 5.5 & 0.74 & 10.58 & 46.86 & 39.28 & 58.43 & 15.15 & 34.34 & 63.36 & 6.73 & 0.12 \\
\hline
\end{tabular}

$\mathrm{NO}_{3}-\mathrm{N} 46.86 \mathrm{mg} \cdot \mathrm{L}^{-1}, \mathrm{PO}_{4}-\mathrm{P} 6.73 \mathrm{mg} \cdot \mathrm{L}^{-1}$, and $\mathrm{K} 39.28 \mathrm{mg} \cdot \mathrm{L}^{-1}$ (Table 2). The nutrient solution used in this study is conventionally used in farms, and it was prepared based on the prescription for the standard nutrient solution for blueberry $\left(\mathrm{NO}_{3}-\mathrm{N} 4.6 \mathrm{mmol} \cdot \mathrm{L}^{-1}, \mathrm{NH} 4-\mathrm{N} 3.4 \mathrm{mmol} \cdot \mathrm{L}^{-1}, \mathrm{PO}_{4}-\mathrm{P} 3.3 \mathrm{mmol} \cdot \mathrm{L}^{-1}, \mathrm{~K} 3.0 \mathrm{mmol} \cdot \mathrm{L}^{-1}, \mathrm{Ca} 4.6 \mathrm{mmol} \cdot \mathrm{L}^{-1}, \mathrm{Mg} 2.2 \mathrm{mmol} \cdot \mathrm{L}^{-1}\right)$ provided by the Gyeongsangnam-do Agricultural Research and Extension Services. The average daily temperature in Jinju during the experiment period was $17.6^{\circ} \mathrm{C}$, the average maximum temperature, $24.1^{\circ} \mathrm{C}$, and the average minimum temperature, $11.6^{\circ} \mathrm{C}$. The surface temperature was $20.9^{\circ} \mathrm{C}$, and the average daily temperature difference was $12.5^{\circ} \mathrm{C}$. The average sunshine hours during the period were 7.08 hours, and the average amount of solar radiation was $12.66 \mathrm{MJ} / \mathrm{m}^{2}$. The accumulated precipitation during the period was $370.6 \mathrm{~mm}$, and the number of precipitation days was 26 days (KMA, 2017).

\section{Growth and substance analysis}

The items of growth analysis include the characteristics of fruit such as sugar content, fruit diameter, the fresh weight of fruit, the total weight of production and the number of fruit, and a functional substances (anthocyanin). The sugar content of fruit was measured using an automatic refractometer (Pocket refractometer PAL-1, Atago, Japan), and the diameter of fruit was measured using digital vernier calipers (Absolute Digimatic 500-182, MItutoyo Co., Japan). The total weight of production and the number of fruit were measured by picking all fruit after 10 weeks of treatment, and collecting ripe fruit only (excluding green fruit). To measure the content of anthocyanin, $5 \mathrm{~g}$ of fresh blueberry was collected and ground using an extraction solution (ethanol:distilled water:hydrochloric acid=70:30:1, V/V/V) using the method suggested by Kim et al. (2011). The extracted solution was centrifuged and the supernatant was collected and diluted to $20 \mathrm{~mL}$. Its absorbance was measured at $520 \mathrm{~nm}$.

\section{Statistical analysis}

The measured data were collected using Microsoft office EXCEL, and were statistically analyzed using SAS 9.4 (SAS Institute Inc., USA). Statistical significance between average values was analyzed using one-way ANOVA and Duncan's multiple range test.

\section{Results and Discussion}

\section{Growth characteristics of fruit}

The growth characteristics of blueberry that were obtained in this study are as shown in Table 3 . The sugar content of the OEW group $\left(10.41^{\circ}\right.$ brix) and the QEW group ( $10.65^{\circ}$ brix) was among the highest, followed by the HEW group ( $10.08^{\circ}$ brix), the control group $\left(9.37^{\circ} \mathrm{brix}\right)$, and the conventional group $\left(9.24^{\circ} \mathrm{brix}\right)$. There was no statistically significant difference between groups treated with effluent emitted from a BFT aquaculture farm, but the sugar content of these groups was statistically significantly higher than that of the control and conventional groups. Considering the result of an 
Table 3. Blueberry growth characteristics: soluble solid content, fruit size (caliber and weight) by treatments of effluent water and fertilizers.

\begin{tabular}{lccc}
\hline \multicolumn{1}{c}{ Treatment } & $\begin{array}{c}\text { Soluble solid content } \\
\left({ }^{\circ} \mathrm{brix}\right)\end{array}$ & $\begin{array}{c}\text { Fruit diameter } \\
(\mathrm{cm})\end{array}$ & $\begin{array}{c}\text { Fruit fresh weight } \\
(\mathrm{g} / \mathrm{ea})\end{array}$ \\
\hline Control & $9.37 \mathrm{~b}^{\mathrm{z}}$ & $1.56 \mathrm{c}$ & $1.92 \mathrm{a}$ \\
Conventional & $9.24 \mathrm{~b}$ & $1.64 \mathrm{~b}$ & $1.80 \mathrm{a}$ \\
OEW & $10.41 \mathrm{a}$ & $1.75 \mathrm{a}$ & $1.83 \mathrm{a}$ \\
HEW & $10.08 \mathrm{a}$ & $1.70 \mathrm{ab}$ & $2.08 \mathrm{a}$ \\
QEW & $10.65 \mathrm{a}$ & $1.72 \mathrm{a}$ & $1.67 \mathrm{a}$ \\
Significance & $* * *$ & $* * *$ & $\mathrm{NS}$ \\
\hline
\end{tabular}

Conventional=Nutrient solution of farm; $\mathrm{OEW}=$ Original effluent water; $\mathrm{HEW}=$ Half strength effluent water; $\mathrm{QEW}=$ Quarter strength effluent water.

${ }^{\mathrm{z}}$ Mean separation within columns of each treatment by Duncan's multiple range test at $p=.05$.

${ }^{\mathrm{NS}}$ Non-significant, ${ }^{* * *} p<.001$.

earlier study that effluent emitted from a BFT aquaculture farm contains components that affect the growth of plants such as nitrogen, phosphorus, potassium and calcium (Kim et al., 2016a), these results in this study indicate that the components of the effluent affect the growth of blueberry. In addition, these results coincide with the results of an earlier study that cultivated cherry tomato with effluent from a BFT aquaculture farm, which indicates that effluent from BFT aquaculture farms is effective to increase the sugar content of fruit vegetables such as cherry tomato as well as fruit plants. (Kim et al., 2017).

The fruit diameter of the OEW group was the highest $(1.75 \mathrm{~cm})$, and that of the HEW group $(1.70 \mathrm{~cm})$ and the QEW group $(1.72 \mathrm{~cm})$ were similar to each other, but there was no statistically significant difference between groups treated with effluent. The fruit diameter of the conventional group $(1.64 \mathrm{~cm})$, and the control group $(1.56 \mathrm{~cm})$ was statistically significantly lower than that of the OEW and QEW groups. These results are similar to those of the sugar content, which indicates that treatment with effluent from aquaculture farms affects the size of blueberry. The fruit fresh weight of the HEW group was the highest (2.08 g), followed by the control group (1.92 g), the OEW group (1.83 g), the conventional group (1.80 g), and the QEW group (1.67 g), but there was no statistically significant difference between the groups. These results show that treatment with effluent from BFT aquaculture farms does not affect much the individual fresh weight of fruit, but affects the size of fruit.

\section{Content of functional substance}

The total content of anthocyanin, a functional substance, in the QEW group was the highest (457.10), followed by the conventional group (444.19), the OEW group (411.68), the control group (356.24), and the HEW group (323.29) (Fig. 1). These results do not coincide with those of an earlier study that the content of a functional substance in vegetables grown using effluent emitted from a BFT aquaculture farm was higher than that of vegetables grown using a conventional method (Kim et al., 2016b). Kim et al. (2016b) reported that the content of anthocyanin in eggplant treated with the original and half-strength effluent from a BFT aquaculture farm was the highest, while the results of this study show that the content of anthocyanin in the HEW group was lower than that in the conventional group. In another study on the accumulation of a functional substance in blueberry that was organically cultivated and grown using a conventional method (Wang et al., 2008), it was found that the content of a functional substance in blueberry organically grown was 


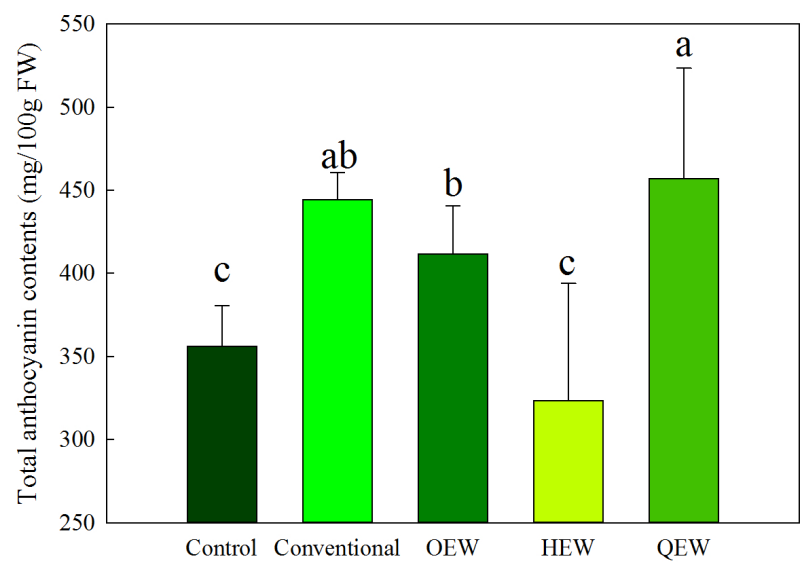

Figure 1. Total anthocyanin contents in blueberry by treatment of effluent water and fertilizers.

Vertical bar means average with standard deviation.

Conventional=Nutrient solution of farm; OEW=Original effluent water; HEW=Half strength effluent water; QEW=Quarter strength effluent water.

Bars with the different letter are significantly different at the $5 \%$ level based on Duncan's Multiple Range Test.

statistically significantly higher than that in blueberry grown using a conventional method. Treatment with effluent from a BFT aquaculture farm is one way of organic farming. The content of anthocyanin in the QEW group was the highest, but that in the HEW group was similar to the control group in this study, which does not coincide with the results of earlier studies that the content of functional substances in tomato, pepper and eggplant grown using effluent from BFT aquaculture farms increased (Kim et al., 2016b; 2017). In this regard, it is necessary to conduct a follow-up experiment on effluent from BFT aquaculture farms that affects the content of anthocyanin in blueberry more systematically, and to identify optimal levels of effluent for different plants or varieties.

\section{Total fruit production}

The results of the total blueberry production per unit tree are as shown in Table 4. The total weight of fruit of the QEW group was the highest (457.10 g), followed by the conventional group (348.15 g), the HEW group (323.29 g), the control group (263.23 g), and the OEW group (241.30 g). The number of fruit of the conventional group was the highest (195),

Table 4. Total blueberry production per plant by treatment of effluent water and fertilizers.

\begin{tabular}{lcc}
\hline \multicolumn{1}{c}{ Treatment } & Total weight $(\mathrm{g})$ & Total number of fruit (ea) \\
\hline Control & $263.23 \mathrm{a}$ & $137.7 \mathrm{a}$ \\
Conventional & $348.15 \mathrm{a}$ & $195.0 \mathrm{a}$ \\
OEW & $241.30 \mathrm{a}$ & $136.0 \mathrm{a}$ \\
HEW & $323.29 \mathrm{a}$ & $176.7 \mathrm{a}$ \\
QEW & $457.10 \mathrm{a}$ & $146.0 \mathrm{a}$ \\
Significant & $\mathrm{NS}$ & NS \\
\hline
\end{tabular}

Conventional=Nutrient solution of farm; $\mathrm{OEW}=$ Original effluent water; $\mathrm{HEW}=$ Half strength effluent water; $\mathrm{QEW}=\mathrm{Quarter}$ strength effluent water.

${ }^{\mathrm{z}}$ Mean separation within columns of each treatment by Duncan's multiple range test at $p=.05$.

${ }^{\mathrm{NS}}$ Non-significant. 
followed by the HEW group (176.7), the QEW group (146), the control group (137.7), and the OEW group (136). In terms of the total production such as the total weight and the number of fruit, there was a difference between the groups treated with effluent from a BFT aquaculture farm and the conventional group, but no statistically significant difference. Thus, it will be necessary to conduct an additional experiment on this.

\section{Conclusions}

As people's awareness of environmental pollution has been raised and pollution sources have been strictly regulated, treating effluent from aquaculture farms has become an urgent issue. In particular, effluent emitted from aquaculture farms that contains organic components from fish causes water pollution. Due to these issues, the aquaculture industry is searching ways to handle effluent from aquaculture farms. Against this backdrop, this study was conducted to find ways to re-use effluent from aquaculture farms for agricultural purposes and thus to address these issues. As people's interest in and consumption of blueberry increase, the size of production areas in Korea has expanded. In this study, effluent from an aquaculture farm was used to cultivate blueberry as a fertilizer, and the results showed that the use of effluent emitted from an aquaculture farm was effective to increase the sugar content and the size of fruit, and that in terms of the production of blueberry, there was no significant difference in the fresh weight and the number of fruit between those grown using effluent and those grown using a conventional method. Based on the results, it can be concluded that the original or diluted effluent water emitted from aquaculture farms can be used as a way of organic farming in agricultural farms, and that, by re-using effluent in the agricultural industry, issues related to effluent from aquaculture farms can be addressed. However, there were some limitations in this study. The components of effluent emitted from aquaculture farms are not consistent as they grow different species of fish. For this reason, the components of effluent need to be identified first, and any components that are low or high need to be adjusted. Additional studies need to be conducted to develop methods of transporting effluent to agricultural farms and to compare its components with those of other organic fertilizers and growth characteristics.

\section{References}

Cho, K.W. 2010, July 03. Food industry, super food 'blueberry' craze. Asia economy, Retrieved from http://www.asiae.co.kr/ news/view.htm?idxno=2010070311521906326

Cho, S.H., J.H. Jeong, M.H. Kim, K.T. Lee, D.J. Kim, K.H. Kim, S.P. Oh, and C.H. Han. 2015. The effects of temperature on maintaining the stability of water quality in biofloc-based zero-water exchange culture tanks. J. Life Sci. 25(5): 496-506.

Kim, H.L., Y.B. Kim, H.D. Kim, J.G. Kim, and Y.H. Choi. 2011. Effect of different soil water potentials on growth properties of northern-highbush blueberry. Korean Soc. Soil Sci. Fert. 44(2):161-167.

Kim, S.J., K.S. Park, S.J. Park, and Y.H. Kwon. 2013, October. Current status of blueberry culture in Korea. Paper presented at the 2013 Fall Conference on Korean Society for Horticultural Science, Korea. Abstract retrieved from http:// www.dbpia.co.kr/Article/NODE06129238

Kim, Y.H., M.R. Huh, J.H. Lee, Y.S. Lee, and H.S. Choi. 2017. Availability verification of effluent from BFT inland aquaculture for urban agricultural fertilizer through cherry tomato cultivation. J. People Plants Environ. 20(4):293-300. DOI: 10.11628/ksppe.2017.20.4.293

Kim, Y.H., S.G. Sohn, Y.S. Lee, H.S. Choi, and M.R. Huh. 2016a. Development of urban agricultural fertilizer of effluent water from BFT inland aquaculture. J. Korean Soc. People Plants Environ. 19(5):403-408. DOI: 10.11628/ ksppe.2016.19.5.403 
Kim, Y.H., S.G. Sohn, Y.S. Lee, H.S. Choi, and M.R. Huh. 2016b. Effect of the effluent waters from BFT inland aquaculture of the growth and fuctional substance contents in 3 types of vegetable crops. J. Korean Soc. People Plants Environ. 19(4):299-303. DOI: 10.11628/ksppe.2016.19.4.299

KMA (Korea Meteorological Administration). 2017, October, 5. Past domestic climate data. Retrieved from http://www. kma.go.kr/weather/climate/past_table.jsp

Lee, S.G. 2001. Pollution of aquaculture fisheries - Overcoming environmental problems in aquaculture farms, raising industrial cohesion. Fishing Port 57:30-34. Retrieved from http://www.riss.kr/link?id=A101530965

Oh, S.Y. 2007. The black marketing craze. Excell. Mark. Cust. 41(9):72-75.

RDA (Rural Development Administration). 2011. Blueberry cultivation and import trends. Retrieved from http://www. nongsaro.go.kr/portal/ps/pst/pstb/pstbc/mngmtDtaDtl.ps?menuId=PS03213\&nttSn=604\&totalSearchYn=Y

Wang, S.Y., C.T. Chen, W. Sciarappa, C. Y. Wang, and M.J. Camp. 2008. Fruit quality, antioxidant capacity, and flavonoid content of organically and conventionally grown blueberries. J. Agric. Food Chem. 56:5788-5794. DOI: 10.1021/ jf703775r CCC: $\$ 40.75$ 